\title{
Postural assessment of school children: an input for the design of furniture
}

\author{
Maria Antónia Gonçalves ${ }^{1}$ and Pedro M. Arezes ${ }^{2}$ \\ ${ }^{I}$ School of Managements and Industrial Studies, Porto Polytechnic Institute, 4480-876 Vila do Conde, Portugal \\ ${ }^{2}$ Production and Systems Department, University of Minho, 4800-058 Guimaraes, Portugal
}

\begin{abstract}
During the last decades of the previous century, school desks with a tilt top have disappeared. The chairs have been designed for sitting upright, with the hip, knees and ankles all at right angles. However, the erect posture cannot be maintained for more than one or two minutes, after which it will result in fatigue, discomfort or poor posture. The main aim of project is to identify the type of furniture that most effectively contribute to adequate neck and back postures of the school children, by carrying out a postural analysis of a sample of school pupils when using three different types of furniture. The postures adopted by school pupils were monitored by video during several activities, such as reading, writing and painting tasks, copying from a blackboard and listening the teacher. Additionally, the characteristics of the adopted postures were assessed by registering the head tilt, flexion of the neck, trunk and hips position. All these aspects were classified and the results were recorded for future analysis. The obtained results seem to point out that the use of a school desk with a tilted table surface resulted in a reduction in trunk and neck flexion, preserving the natural lordosis in the lumbar and cervical regions. Accordingly, it can be concluded that there are alternatives to consider in the furniture design in order to eliminate tensions and, consequently, to improve children's wellbeing.
\end{abstract}

Keywords: ergonomics, schoolchildren, furniture, design, posture

\section{Introduction}

School furniture, particularly chairs, is designed for sitting upright, with knees and ankles the hip all at right angles. This posture of reference is adopted considering the optimal posture that is referred in all of the ISO standard series dealing with anthropometrics and furniture dimensions. However, this erect sitting posture can not be maintained for more then one or two minutes, resulting in fatigue, discomfort and poor postures [13].

Young children spend a lot of time at school and, most of the time, they are seated in a forward leaning position carrying out activities like writing, reading and drawing or painting. School children also tend to adopt a backward position leaning against the backrest, while resting or attending to the teacher [1].
When leaning forward over the desk, the hip-joints are bended about 40-50 degrees. Keegan (1953) demonstrated, by using a series of x-rays analysis, that the natural physiological position of the spine can be achieved with the thigh angle stem to about 135 degrees [7]. In this position, the lumbar curve is retained and the muscles are relaxed and wellbalanced. A sitting posture that approaches this natural resting position, is calling a "Balanced Seating" [13].

For promoting this natural posture, the seat must be tilted forward and the desk must be sloped. In this position the opposing muscle groups are balanced and the lumbar curve is preserved. Additionally, the back is straight, the joint angles are open and the muscles are relaxed $[3,4]$. A desk with $10^{\circ}$ inclination required less trunk and neck flexion [6, 16]. School children did not appreciate lower furniture

\footnotetext{
${ }^{1}$ Corresponding author: mag@eu.ipp.pt
} 
with backward-sloped chair and a pronounced back support [8].

On the other hand, the activities of reading and writing on tables with horizontal surface require a strong head tilting forward, in order to get an appropriate view of the work. This movement of the neck is highly damaging to the cervical spine. Spending long periods in the sitting position with lumbar flexion of at least $30^{\circ}$, bent forward in more than $50 \%$ of class time, may increase the risk of neck and back pain of children [15].

Wall et al. observed that children, in an attempt to find the best distance for viewing the work material, adopt positions of head tilt to the front of high angular values. This position requires the muscles of the neck to an eccentric contraction to counteract the weight of the head, keeping the balance [16].

Understanding that exists a connection between the postures adopted, the activity, the place where such activity occurs, the context in which it develops, it is understood that the internal factors and external factors influence the work situation.

The school furniture, as a part of the physical space of a school, becomes an essential and highly important issue within this environment. It will influence the physical and psychological comfort of the school children and consequently with a direct impact on their health and learning output.

The main aim of this study was to identify the effect of the type of furniture on the neck and back postures of the school children, by applying a postural analysis of the observed school children when using two different types of furniture.

\section{Method}

The postures adopted by school children were observed for three different situations, namely: (a) using traditional furniture (flat table and chair with $5^{\circ}$ backward tilted); (b) with the use of a traditional chair ( $5^{\circ}$ backward tilted) and table $12^{\circ}$ tilted; (c) with a chair with seat $12^{\circ}$ sloped forward and a table top $12^{\circ}$ tilted (figure 1 ).

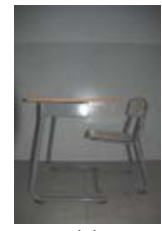

(a)

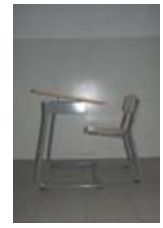

(b)

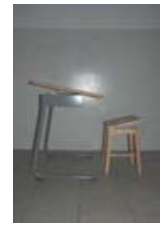

(c)
Fig. 1 - The furniture combinations analysed.
Regarding methodology, the sitting posture of the school children were video monitored during several activities, such as reading, writing and painting tasks, copying from a blackboard and working with a laptop computer.

The video analysis technique, used in this project, was previously validated by Murphy et al. (2002) by comparing the data obtained with the method of observation PEO (Portable Ergonomic Observation). The technique seems to provide very accurate data of the attitudes of children in class, since the camera is placed laterally, with full vision of the area of the trunk and thighs. However, this method is only possible to apply for the analysis of a small group of people, since it is a very time consuming method, requiring a long period of time for each observation [15].

\subsection{Participants}

Twenty students from $2^{\text {nd }}$ to $4^{\text {th }}$ grade, selected from several schools of the first cycle of education of Vila Nova de Gaia, in Portugal, were randomly chosen and were observed for 15 minutes per child, during the various activities in the classroom, and using three combinations of furniture for the same task. This was achieved sue to the collaboration of the involved teachers, which allowed the task remained unchanged during the 45 minutes of observation of each child.

\subsection{Apparatus}

The video recording was made with the use of a video camera and a tripod, placed laterally at a distance of about 2 meters from the observed child. School children were observed during one week, in order to collect data regarding the highest number of activities that are performed in the classroom.

\subsection{Procedure}

Subsequently, the video records were analyzed with a registration of the type of activity that was being held and its duration and measuring the angle between torso and thighs and the angle of the neck flexion.

Based on the methodology used by Murphy et al. (2002) angles were measured through the used of a transparent sheet of acetate [15], in which were drawn the analysed angles (a $90^{\circ}$ angle to study the angle between the trunk and thighs and two angles of 
$30^{\circ}$ and $45^{\circ}$ for the neck flexion), from the frontal plane. This sheet was placed directly on the computer screen and adjusted to the plan throughout the analysis, as the child moved backward or forward. In situations where the thighs were not supported on the seating surface, the frontal plane was replaced by the right angle formed by the thighs.

At intervals of 15 seconds, the video was stopped and records conducted for each body area under study and for cases in which the position was not changed. If in this period occurred a change in posture, it was recorded the duration of the child posture till he/she moved to the next posture.

Despite the several methods of measuring the angles of trunk flexion using photos referenced in the literature, we chose to use the method of measuring angles proposed by Chaffin et al. (1999) [5], with some slight adaptations. The Chaffin's technique calculates the angle of trunk flexion by measuring by drawing a line crossing the centers of the shoulder joint and hip with the vertical. In the used method the angle is the result of crossing the line joining the centers of the shoulder joint and hip, with the line connecting the center of the hip with the knee joint center. The angle of neck flexion was determined by the angle between the vertical line passing through the cervical vertebra $\mathrm{C} 7$ and the tragus (the cartilaginous ridge opposite the orifice of the ear) [2] (figure 2).

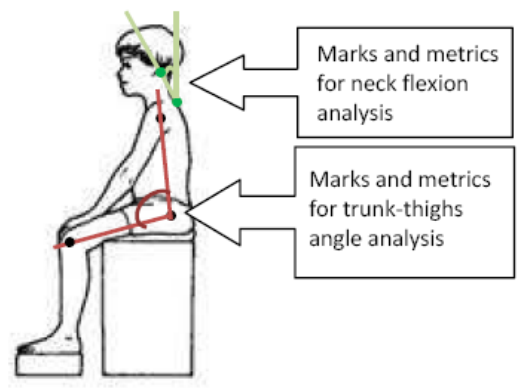

Fig. 2 - Marks and metrics for analysis

\section{Results}

The time, in seconds, during which the child maintained a determined posture, within the ranges under study, and each of the combinations of furniture used, were recorded into a MS Excel file. As mentioned previously, a video of 15 minutes was recorded for each of the furniture combinations and for each of the 20 children studied (see figure 3 ).

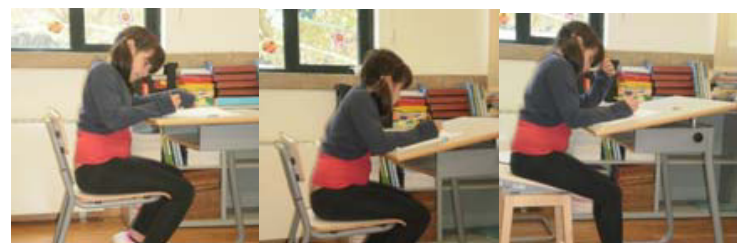

Fig. 3 - Images of the situation under analysis

Considering the total duration of the observed tasks, the time associated to each posture was converted into a percentage, and the results are presented in Table 1.

\section{Discussion}

As already concluded by Mandal et al. in some of their published studies $[10,12,13,14]$, the best posture for the trunk is achieved by using a combination of furniture with tilted tables and seats [13]. Actually, from table 1 , it is possible to see that only in $4.7 \%$ of the time it was observed an angle of less than $90^{\circ}$ and this percentage regards the observation of the posture for a specific child.

The combination (b) also proved to be a good solution as compared to the traditional horizontal tops. It should also be highlighted that, during the study, children were asked to express their opinion about the more comfortable combination. Ninety five per cent of the children, i.e., nineteen out of twenty, reported that they liked the combination (b) - Table $12^{\circ}$ tilted and a chair with $5^{\circ}$ backward tilted - and only one seemed to feel more comfortable with the combination (a) (traditional model).

The traditional model seems to be more punitive for the seated posture. Children spend almost $75 \%$ of the time with flexion angles between torso and thighs below $90^{\circ}$, thus causing a high pressure on the intervertebral discs.

When analyzing the neck flexion, it is possible to notice that postures are essentially dependent on the activities that were being performed. When the child is looking at the board or hearing the teacher, the head is upright and the flexion degree of the neck is below $30^{\circ}$. However, in reading and writing activities, children tend to increase the flexion of their neck, to get an appropriate view of the work they are doing.

It appears that with the combinations (a) and (b), most of the time, children flex their neck more than $45^{\circ}$, which represents a harmful posture for the cervical spine. In this respect, the combination (c) seems to be the most favourable combination, as it requires 
a smaller flexion of the neck, reaching values between 30 and $45^{\circ}$, for more than $50 \%$ of the analysed cases.

The combination (a), that is the most common combination in basic education schools in Portugal seems, once again, to be the worst solution from an ergonomics point of view.

The focal length, the distance between children's' eyes and the table, seems also to be an important variable for both the trunk and neck flexion. This finding comes from the fact of having used furniture fixed dimensions in children from 7 to 10 years, with notable differences in stature and to verify that the higher they were the higher tendency to flex the trunk and neck they have.

In the cases of the lowest children, for whom the table height was slightly above the recommended height (elbow level), no such need was observed, enabling that these children can adopt more favorable postures.

This is an issue that should be analysed with further research in order to get more detailed and reliable conclusions.

The focal length should be between 20 and $30 \mathrm{~cm}$ of the object view, assuming that it is at a $90^{\circ}$ angle on the line of sight [11], which is the line between the eye and the object observed.

The angle of comfort can be described by a $30^{\circ}$ cone around the normal line of sight, i.e. when the individual is not stared at any specific point and his vision is directed forward. Eye movements of 15 degrees above or below this line, is considered comfortable and require no effort. Outside these limits, the segments of the head and neck are forced to move [9].

Table 1

Percentage of time spent by children, for each defined postures and furniture combinations

\begin{tabular}{|c|c|c|c|c|c|}
\hline \multirow{2}{*}{$\begin{array}{l}\text { Furniture } \\
\text { combinations }\end{array}$} & \multicolumn{2}{|c|}{ Trunk-Thighs Angle } & \multicolumn{3}{|c|}{ Neck Flexion Angle } \\
\hline & $<90^{\circ}$ & $\geq 90^{\circ}$ & $\leq 30^{\circ}$ & $30^{\circ}-45^{\circ}$ & $\geq 45^{\circ}$ \\
\hline Combination (a) & $74.1 \%$ & $25.9 \%$ & $11.5 \%$ & $22.8 \%$ & $65.8 \%$ \\
\hline Combination (b) & $59.1 \%$ & $40.9 \%$ & $8.2 \%$ & $19.1 \%$ & $72.7 \%$ \\
\hline Combination (c) & $4.7 \%$ & $95.3 \%$ & $8.8 \%$ & $52.4 \%$ & $38.8 \%$ \\
\hline
\end{tabular}

\section{Conclusions}

The obtained results seem to point to a reduction in trunk and neck flexion, preserving the natural lordosis in the lumbar and cervical regions, by using furniture (table and chair) with inclined surfaces.

The inclined surfaces of the table in the direction of the user and the seat forward are alternatives to consider in order to eliminate tensions and to improve children's wellbeing.

The school furniture should be designed to accommodate the natural resting position, in which opposing muscles are well balanced.

The resulting posture will tend to improve performance, efficiency and children's well-being.

\section{References}

[1] Aagaard-Hansen J, Storr-Paulsen A., The working positions of schoolchildren. Technical Note. Applied Ergonomics, 25 (1), 1994, 63-64

[2] Ankrum, D.R., Nemeth, K.J., Head and Neck Posture at Computer Workstations-What's neutral? Proceedings of the 14th Triennial Congress of the International Ergonomics Association, vol. 5, 2000, pp. 565-568)

[3] Bendix, T. (1984), Seated trunk posture at various seat inclinations, seat heights and table heights, Human Factors 26, 1984,pp. 695-703

[4] Bridger, R.S., Postural adaptations to a sloping chair and work surface, Human Factors 30, 1988, pp. 237-247.

[5] Chaffin, Don B., Andersson, Gunnar B. J. and Martin, Bernard J., in "Occupational Biomechanics, 3rd Edition, Jonh Wiley \& Sons, Inc., 1999.

[6] Freudenthal A., van Riel M.P., Molenbroek J.F.M., Snijders C.J., The effect on sitting posture of a desk with a ten-degree inclination using an adjustable chair and table, Applied Ergonomics 22, 1991, pp. 329-336

[7] Keegan, J. J., Alterations of the lumbar curve related to posture and seating. Bone it Surg, v. 35, 1953, pp.589-603 
[8] Knight, G., Noyes, J., Children's behaviour and the design of school furniture. Ergonomics 42, 1999, 747-760.

[9] Kromer, K. H. E.; Grandjean, E. Fitting the task to the human: a textbook of occupational ergonomics. 5 ed. London: Taylor \& Francis, 1997

[10] Mandal, A.C., Work chair with tilting seat, Ergonomics 19 (2), 1976, pp.157-164

[11]Mandal, A.C., The Seated Man (Homo Sedens), Applied Ergonomics, 12(1), 1981, 19

[12] Mandal, A.C., The correct height of school furniture, Human Factors (USA) 24, 1982, pp. 257-269
[13] Mandal, A.C., The influence of school furniture height on backpain, Behaviour and Information Technology, n³, 247, London, 1987

[14] Mandal, A.C., The prevention of back pain in school children, in Lueder, Rany \& Noro, Kageyu (edits). The Ergonomics of seating, London, Taylor and Fancis, 1994, pp.269-277

[15] Murphy, S., Buckle, P. \& Stubbs, D., The use of the portable ergonomic observation method (PEO) to monitor the sitting posture of schoolchildren in the classroom. Applied Ergonomics, 33, 2002, 365-370.

[16] de Wall M., van Riel M.P., Snijders C.J., van Wingerden J.P. , The effect on sitting posture of a desk with a 10 degree inclination for reading and writing, Ergonomics 34, 1991, 575-584. 